\title{
Autogenous shrinkage revisited
}

Jensen, O.M.

\section{Published in:}

Concrete Durability and Service Life Planning

Link to article, DOI:

10.1007/978-3-030-43332-1_17

Publication date:

2020

Document Version

Peer reviewed version

Link back to DTU Orbit

Citation (APA):

Jensen, O. M. (2020). Autogenous shrinkage revisited. In Concrete Durability and Service Life Planning:

Proceedings of ConcreteLife'20 (Vol. 26, pp. 84-88). Springer. RILEM Bookseries https://doi.org/10.1007/978-3030-43332-1_17

\section{General rights}

Copyright and moral rights for the publications made accessible in the public portal are retained by the authors and/or other copyright owners and it is a condition of accessing publications that users recognise and abide by the legal requirements associated with these rights.

- Users may download and print one copy of any publication from the public portal for the purpose of private study or research.

- You may not further distribute the material or use it for any profit-making activity or commercial gain

- You may freely distribute the URL identifying the publication in the public portal

If you believe that this document breaches copyright please contact us providing details, and we will remove access to the work immediately and investigate your claim 


\title{
Autogenous Shrinkage Revisited
}

\author{
O.M. Jensen (omj@byg.dtu.dk) \\ Department of Civil Engineering, Technical University of Denmark, Lyngby, Denmark
}

Keywords: Autogenous, shrinkage, deformation, RH-change, cracking

\section{INTRODUCTION}

In the 1990s it became generally accepted in the scientific community that autogenous shrinkage is a major reason for cracking observed during hardening of high-performance concrete [1,2]. Within this decade suitable measurement techniques to identify autogenous deformation were developed, a large amount of scientific studies on the phenomenon were done all over the World, and various methods to mitigate its adverse effects were tested [3]. Today, about 25 years later, clearly the general knowledge on autogenous shrinkage and its mitigation strategies are extensive, but practice is slow to adopt it. To some extent cracking is in practice considered part of the nature of concrete. In this presentation an overview is given regarding mitigation of autogenous shrinkage in the cementitious binder. Certainly cracking, including that generated by autogenous shrinkage, can be, and should be minimized.

\section{EXPERIMENTAL DETAILS}

Experiments were done with a high-performance cementitious mixture consisting of: White Portland cement (Blaine surface: $419 \mathrm{~m}^{2} / \mathrm{kg}$, Bogue composition by mass-\%: $\mathrm{C}_{3} \mathrm{~S}: 66.1, \mathrm{C}_{2} \mathrm{~S}: 21.2$, $\mathrm{C}_{3} \mathrm{~A}: 4.3, \mathrm{C}_{4} \mathrm{AF}: 1.1, \mathrm{CaSO}_{4}$ : 3.4, free $\mathrm{CaO}: 2.0, \mathrm{Na}_{2} \mathrm{O}$ eq.: 0.020), dry silica fume (BET surface $20 \mathrm{~m}^{2} / \mathrm{g}$, composition by mass-\%: $\mathrm{SiO}_{2}: 89.9$, LOI: $2.9, \mathrm{Na}_{2} \mathrm{O}$ eq.: 1.7 ), and a dry sodium naphthalene sulphonate superplasticizer. Water/cement-ratio is 0.30 , the silica fume/cement ratio is $20 \%$, and superplasticizer/(cement+silica fume) is 0.010 . For mortars quartz sand $0-2.5 \mathrm{~mm}$ with a water absorption of $0.1 \%$ was used. By volume the mortars contain $60 \%$ aggregate.

The methods for measuring development of autogenous properties and cracking sensitivity are described in [2].

\section{RESULTS}

Measurement results of autogenous RH-change, autogenous deformation and stress build-up during restrained hardening are shown in Figs. 1, 2 and 3.

As seen the autogenous RH drops to approximately $80 \% \mathrm{RH}$ after two weeks. It is expected that the RH will not develop much further from this level, even during years of sealed hardening. The observed, slight variation in curvature from 1 to 3 days is related to the silica fume [2]. The RH is a direct measure of the thermodynamic free-energy $(\mathrm{G}[\mathrm{J} / \mathrm{mol})])$ state of the water, which at $30^{\circ} \mathrm{C}$ becomes:

$G=G^{\ominus}+R T \ln (a)=G^{\ominus}+R T \ln \left(\frac{p_{s}}{p^{\ominus}} \cdot R H\right)=G^{\ominus}+R T \ln (0.042 \cdot R H)$

(R: Gas constant [J/mol/K), T: Temperature [K], a: acitivty [-], ө: standard state, s: staurated) As such, the reduction in $\mathrm{RH}$ has the consequence that the free energy of the water is lowered and it becomes less reactive. Though this may not be the cause of the generaly observed limiting autogenous $\mathrm{RH}$ of about $75-80 \%$, it does significantly influence hydration kinetics [2]. 
Experiments have indicated two phenomena to be involved in the autogenous RH-lowering: 1) Dissolution of salts in the pore water, and 2) formation of menisci. Salts dissolved in the pore water may account for a couple of \% RH-lowering, i.e. most of the RH-lowering observed in Fig. 1 will be caused by menisci formation.

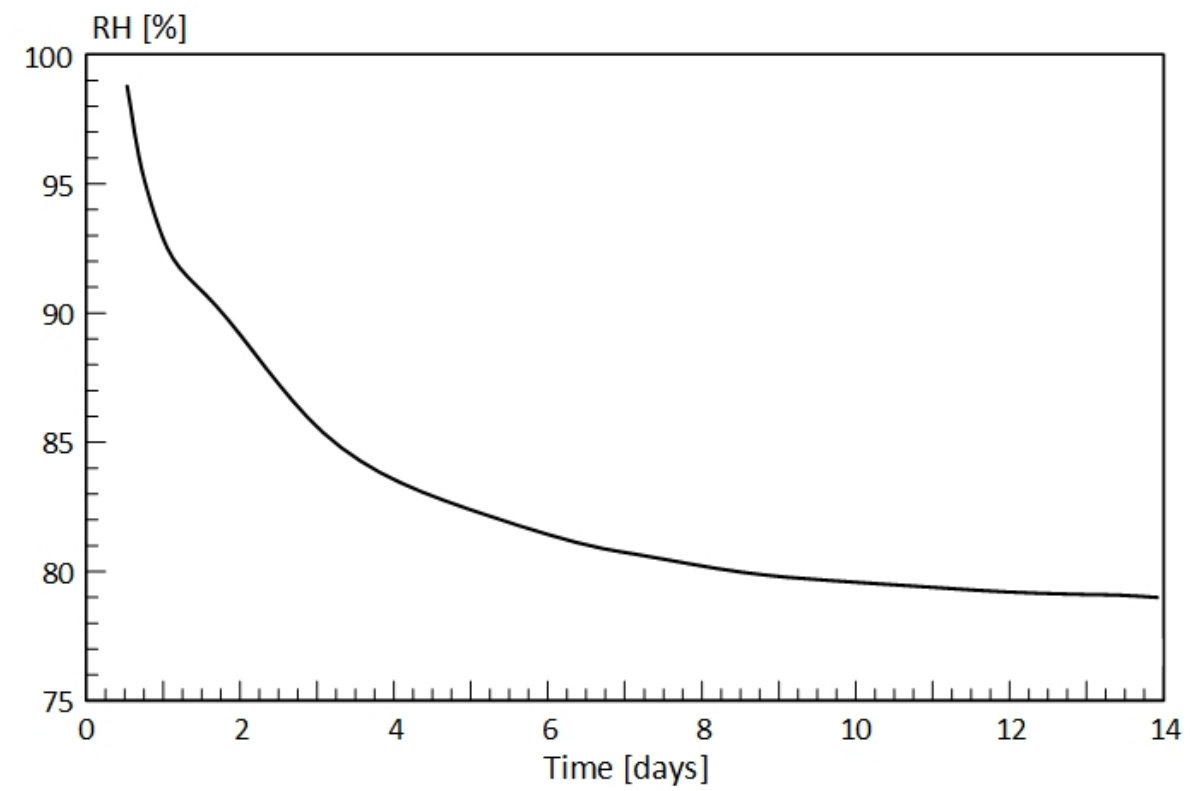

Figure 1. Autogenous RH-change of cement paste with w/c=0.30 and $20 \%$ silica fume addition. Temperature $30^{\circ} \mathrm{C}$.

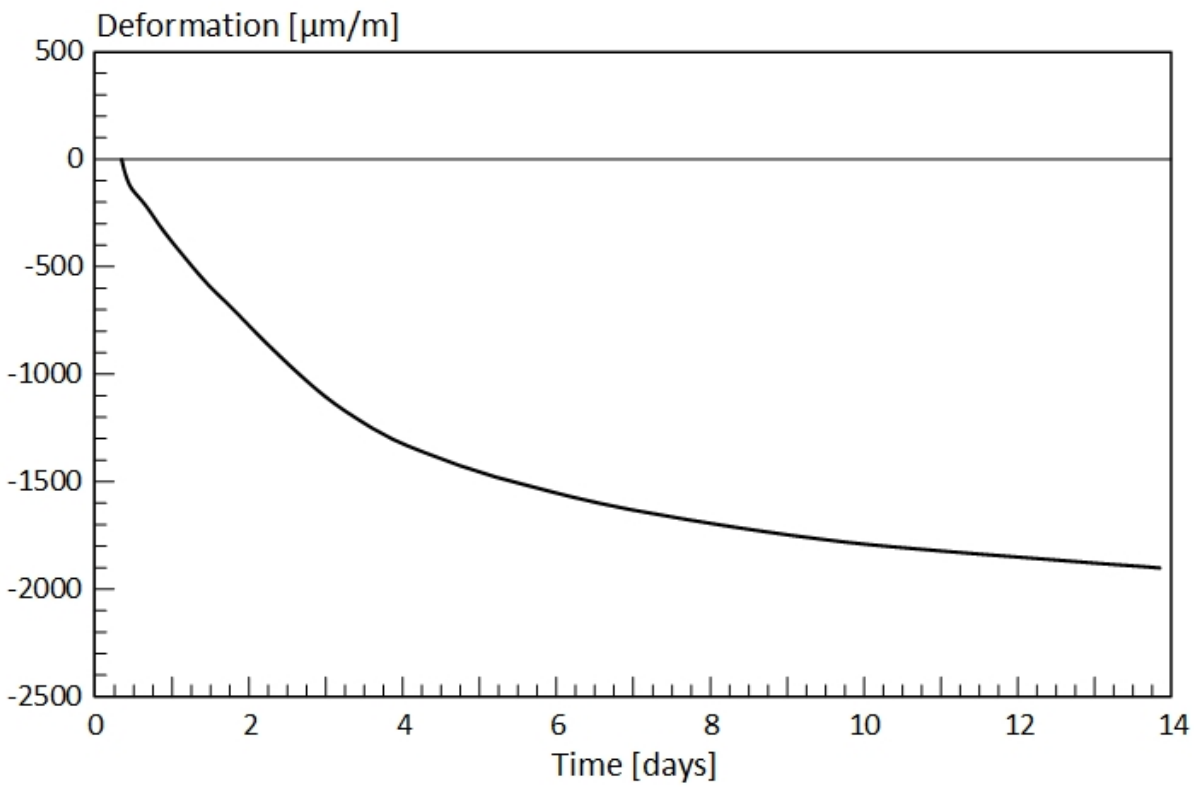

Figure 2. Autogenous deformation after setting of cement paste with w/c=0.30 and $20 \%$ silica fume addition. Temperature $30^{\circ} \mathrm{C}$. 
The menisci will also generate tensile stresses in the pore water $\left(\sigma_{c a p}[\mathrm{~Pa}]\right)$ which are related to the RH through the Kelvin and Laplace equation:

$\sigma_{\text {cap }}=-\frac{R T}{V_{m}} \ln (R H)=-140 \mathrm{MPa} \cdot \ln (R H)\left(\right.$ at $\left.30^{\circ} \mathrm{C}\right)$

$\left(V_{m}:\right.$ molar volume of water $\left.\left[\mathrm{m}^{3} / \mathrm{mol}\right]\right)$

An RH-lowering from e.g. 100 to $80 \%$, completely due to menisci formation, will according to this equation be related to an increase in the pore water tensile stress to approximately $30 \mathrm{MPa}$. Such tensile stresses in the pore water will lead to compressive stresses in the solid skeleton and shrinkage of the cementitious material. Calculative conversion of the pore water tensile stresses into outer shrinkage is not simple as it is influenced by many factors, of which several are illknown: Porosity, degree of saturation of the pores, elastic properties of the solid components, the structure of the composite material, creep, and in the early ages where autogenous RH-change and deformation are particularly active, the microstructure is developing in parallel with the autogenous RH-change and deformation. Furthermore, there are deformation mechanisms active which are not related to menisci stresses, such as shrinkage due to dissolution of restraining components in the solid material or expansion caused by the growth pressure of precipitating components.

Experimentally, in contrast with autogenous RH-change, autogenous deformation is not an absolute measurement, and this causes an additional problem: A “zero-point" for the deformation has to be defined. This is a difficult task as there is no well-defined state for this. The only meaningful option is to measure deformation from the time where the cementitious material transforms from a liquid to a solid, i.e. formally at the point of setting (final set). Obviously significant uncertainty is related to this since this liquid-solid transformation to some extent is smooth rather than instantaneous. A further and very considerable contribution to the complexity of simulation and interpretation of autogenous deformation measurements is that the deformation rate (in the form of shrinkage) reaches very high values before and up till around setting. No matter if the "time zero" is chosen from a physical setting measurement or if it is rather done by interpretation of autogenous deformation measurements the uncertainty related to it may cause a major shift on the deformation values. Luckily it has less consequence on calculated stress buildup during restrained deformation since the creep ability of the material is very high at this early point.

As seen in Fig. 2 the measured autogenous deformation occurs as shrinkage throughout which develops in a smooth and monotonous way. After two weeks almost $2000 \mu \mathrm{m} / \mathrm{m}$ of shrinkage has been generated. This is much more than the expected tensile strain capacity [2]. Apart from this, no particular, characteristic features are observed in Fig. 2.

Fig. 3 illustrates the build-up of tensile stresses during sealed, restrained hardening. After an initial, fast stress build-up, it slows down, but before it stabilizes, the mortar cracks, and the stresses are relieved.

The curves shown in Figs. 1-3 can be considerably changed by modification of the hardening temperature or in the composition of the paste or mortar. As shown in the literature it is possible 
by routine and by simple means to almost completely stop the autogenous RH-change, turn the autogenous shrinkage completely into expansion (or minimize it), and to avoid the stress build-up and cracking during restrained hardening [2]. Though it may not be possible to usefully predict autogenous shrinkage and stress build-up, or even reliably model the internal relations between the autogenous properties, sufficient knowledge does exist to safely control these phenomena.

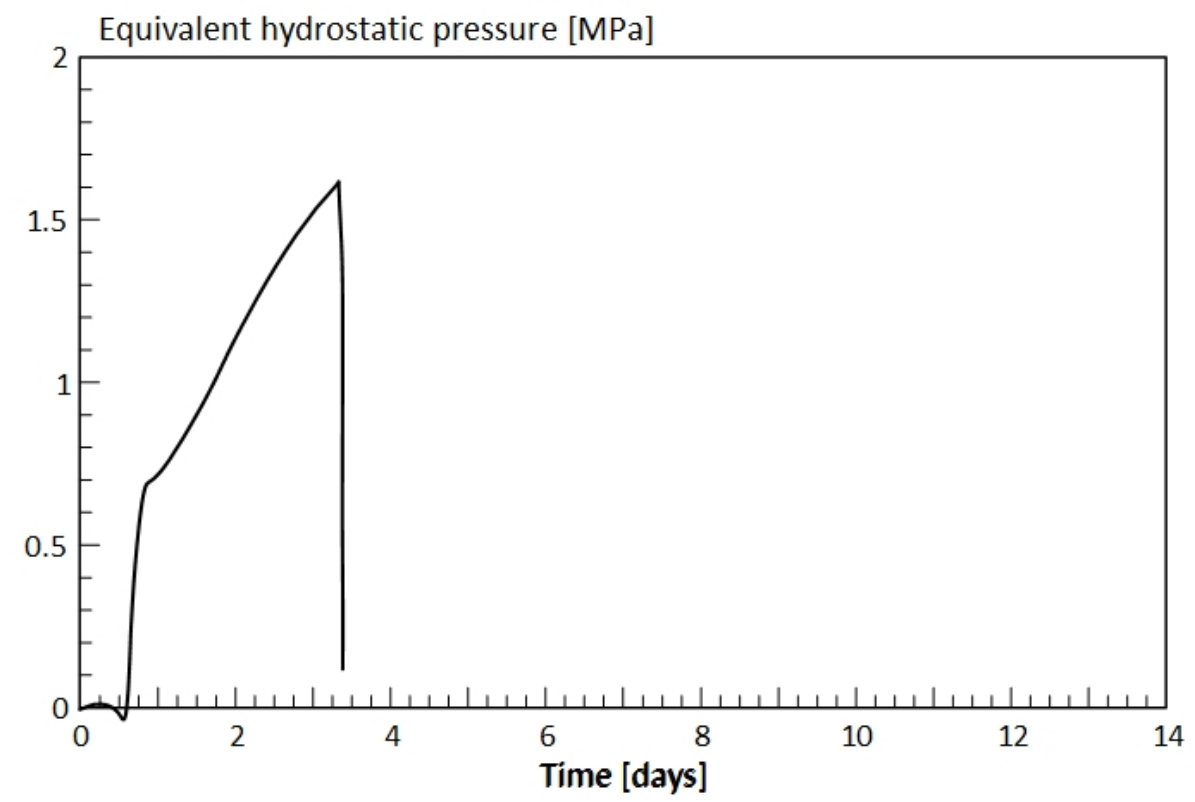

Figure 3. Equivalent hydrotstatic pressure developed during restrained, sealed hardening in an annular shrinkage gauge, ASG, by mortar with w/c=0.30, 20\% silica fume addition, and 60\% aggregate by volume. Temperature $20^{\circ} \mathrm{C}$.

\section{SUMMARIZING COMMENTS}

Since high-performance concrete was introduced into the market more than 30 years ago a lot of knowledge related to its autogenous material properties have been gained. Today we are able to reliably measure and control these properties on a scientific basis, and we do have a basic chemical and physical understanding of the underlying mechanisms involved. However, we still lack sufficient knowledge to reliably predict these phenomena by modeling. This remains a task to be accomplished by future efforts.

\section{REFERENCES}

1. Aïtcin, P.-C. "High-performance concrete”, E \& FN Spon, London, UK, 1998.

2. Jensen, O.M. “Autogenous Phenomena in Cement-Based Materials”, DSc thesis, Aalborg University, Aalborg, Denmark, 2005.

3. Bentz, D.P. and Jensen, O.M. “Mitigation strategies for autogenous shrinkage cracking”, Cement \& Concrete Composites, 26, 2004, pp. 677-685. 